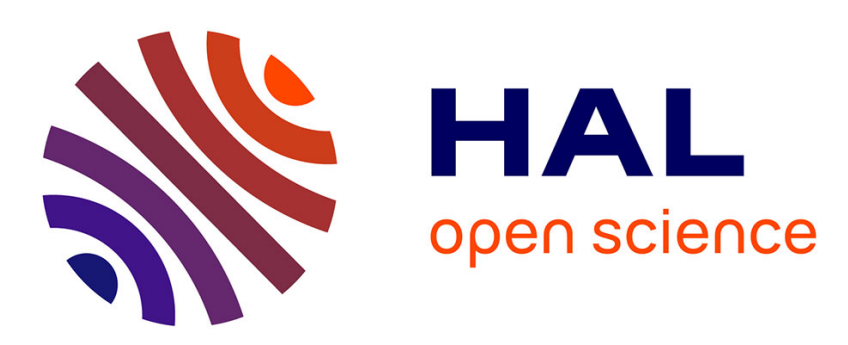

\title{
Effect of dicumyl peroxide concentration on the polymerization kinetics of a polysilazane system
}

d'Elia Raffaele, Gilles Dusserre, Sylvie del Confetto, Nicolas Eberling-Fux, Cédric Descamps, Thierry Cutard

\section{- To cite this version:}

d'Elia Raffaele, Gilles Dusserre, Sylvie del Confetto, Nicolas Eberling-Fux, Cédric Descamps, et al.. Effect of dicumyl peroxide concentration on the polymerization kinetics of a polysilazane system. Polymer Engineering and Science, 2018, 58 (6), p.859-869. 10.1002/pen.24638 . hal-01700705

\section{HAL Id: hal-01700705 https://imt-mines-albi.hal.science/hal-01700705}

Submitted on 6 Nov 2018

HAL is a multi-disciplinary open access archive for the deposit and dissemination of scientific research documents, whether they are published or not. The documents may come from teaching and research institutions in France or abroad, or from public or private research centers.
L'archive ouverte pluridisciplinaire HAL, est destinée au dépôt et à la diffusion de documents scientifiques de niveau recherche, publiés ou non, émanant des établissements d'enseignement et de recherche français ou étrangers, des laboratoires publics ou privés. 


\title{
Effect of Dicumyl Peroxide Concentration on the Polymerization Kinetics of a Polysilazane System
}

\author{
Raffaele D'Elia, ${ }^{1}$ Gilles Dusserre, ${ }^{1}$ Sylvie Del Confetto, ${ }^{2}$ Nicolas Eberling-Fux, ${ }^{3}$ Cedric Descamps, ${ }^{3}$ \\ Thierry Cutard ${ }^{1}$ \\ ${ }^{1}$ Institut Clément Ader (ICA), Université de Toulouse, CNRS, Mines Albi, UPS, INSA, ISAE-SUPAERO, \\ Campus Jarlard, Albi, CT CEDEX 09, 81013, France \\ ${ }^{2}$ Université de Toulouse; CNRS, Mines Albi; Centre RAPSODEE - UMR CNRS 5302; Campus Jarlard, \\ Albi, F-81013, France \\ ${ }^{3}$ Matériaux et Procédés CMC, CMB, SAFRAN Ceramic, Les 5 Chemins, 33185 Le Haillan Cedex
}

\begin{abstract}
The effect of dicumyl peroxide (DCPO) concentration on the polymerization kinetics of a polysilazane system has been investigated through DSC analyses. DCPO acts as polymerization initiator by activating the polyaddition of vinyl groups. The overall heat of reaction is found to be a linear function of the DCPO concentration above $1.5 \mathrm{wt} \%$, due to the addition of the heat of fully initiated polymerization and the heat of DCPO decomposition. Below 1.5 wt\% of DCPO, the polymerisation of polysilazane is not fully initiated and only part of the reaction occurs. The resulting overall heat of reaction is therefore lower than that provided by the linear law valid for higher concentrations. A two-reaction kinetic model built on this interpretation leads to a satisfactory representation of the DSC analyses performed for each DCPO concentration between 0.1 and $20 \mathrm{wt} \%$.
\end{abstract}

\section{INTRODUCTION}

Discovered in 1885 [1], polyorganosilazanes encompass a wide variety of silicon carbo-nitrides precursors utilized since the 1950 s to prepare ceramic materials $[2,3]$ from a single component [4]. Processed at the liquid state, they are particularly well suited for the preparation of Ceramic Matrix Composites (CMC) by Polymer Impregnation and Pyrolysis (PIP) [5-7]. Indeed, this multi-step process involves first the injection of the polymer into a fibrous preform and then the ceramization of the matrix through the pyrolysis of the precursor. The present work is a contribution to the optimization of CMC processed by PIP.

A first step of optimization was performed thanks to several works [8-13] aimed to reduce the volatilization of silazane oligomers in polyorganosilazanes formulations. Higher molecular weights were thereby achieved, together with denser polymers in the intermediate material and denser ceramics in the final product. The general molecular structure of polysilazanes is shown in Fig. 1, in an oversimplified way. By changing $R_{1}$ and $R_{2}$ groups, it is possible to adjust the electronic, optical and rheological properties of the material [14].

More recently, the studies focused on the mechanical and physical in-use properties of polysilazane-derived ceramics [15-18] or on the reactions involved in the polymer-to-ceramic

Correspondence to: G. Dusserre; e-mail: dusserre@mines-albi.fr Contract grant sponsor: DGAC; contract grant number: 1554448A. transformation [19]. However the literature related to the processing properties of the precursors is much less detailed, except properties related to pyrolysis step [5, 6]. A few papers investigate the properties of the intermediate polymer. In particular, viscosity is a key feature to design and optimize the PIP process, and is obviously strongly dependent on polymerization. The viscoelastic behavior of polysilazane derived preceramic polymers was investigated by Flores et al. [20, 21] and D'Elia et al. [22]. From an industrial point of view, optimizing the process means to reduce the processing time without affecting the material quality, and inter alia requires the crosslinking kinetics to be known, minimized and controlled. Crosslinking of polysilazanes is usually performed by heating at $100-250^{\circ} \mathrm{C}[23,24]$, or alternatively by UV radiation $[25,26]$.

Several reactions are involved in the crosslinking mechanism [27] (cf. section "Polysilazane Crosslinking Chemistry"), and some of them can be promoted using the suitable initiator or catalyst. For instance, Flores et al. [20] used tetra- $n$-butylammoniumfluoride to select a crosslinking mechanism involving dehydrogenation with $\mathrm{Si}-\mathrm{H}$ and $\mathrm{N}-\mathrm{H}$ groups to control the glass transition temperature, viscoelastic behavior and thermal stability of the polymer in order to optimize the processing of nonoxide ceramic fibers.

For processing CMC by PIP process, other mechanisms involving reactions without gazeous products (for instance polyaddition of vinyl groups) are more suitable to limit the matrix porosity.

Faster kinetics at lower temperature are made possible by adding a radical initiator, such as organic peroxide, most of the time dicumyl peroxide (DCPO) [24, 28-31], which is able to initiate polyaddition of vinyl groups [32]. The DCPO concentration recommended to reduce the crosslinking temperature ranges between 0.01 and 5 wt $\%$ [33-35], but a comprehensive study on the effect of peroxide concentration on polymerization kinetics remains mandatory in the framework of material and process optimization.

DCPO is widely used as crosslinking agent in the polymer industry. Owing to a very exothermal heat of reaction (between 666 and $868 \mathrm{~J} \cdot \mathrm{g}^{-1}$ [36-40]), DCPO decomposition kinetics has been thoroughly studied in many conditions. In most cases, a pseudo-first order kinetic is reported, with reaction order between 3/4 and 1 [36-40]. However DCPO decomposition kinetics was proved to be sensitive to environment [41]: in the absence of oxygen, DCPO decomposition follows a pseudo-first order kinetics model, whereas an autocatalytic model is more adequate in the presence of oxygen. 


$$
\left[\begin{array}{ll}
\mathrm{R}_{2} & \mathrm{H} \\
\mathrm{I} & \mathrm{I} \\
\mathrm{Si} & -\mathrm{N} \\
\mathrm{I} &
\end{array}\right]_{\mathrm{n}}
$$

FIG. 1. General molecular structure of a polysilazane system.

The scope of the present paper is to analyze the changes in the polymerization kinetics of a polysilazane system with different DCPO concentrations, with the aim to identify the optimal value and to account for DCPO concentration in a crosslinking kinetic model, on the basis of the autocatalytic model identified in [22] for a DCPO concentration of $1 \mathrm{wt} \%$.

\section{EXPERIMENTAL}

The commercial polysilazane under study is the Clariant ${ }^{\circledR}$ $\mathrm{KiON}^{\circledR}$ Ceraset $^{\circledR}$ PSZ 20. Stored in a dark, cool $\left(4^{\circ} \mathrm{C}\right)$ and dry place, the shelf-life of this pale yellow liquid is 6 months [23]. Its density ranges between 1 and $1.1 \mathrm{~g} \cdot \mathrm{cm}^{-3}$, and its viscosity between 180 and $750 \mathrm{mPa} \cdot \mathrm{s}$ at $20^{\circ} \mathrm{C}$. Once crosslinked between 100 and $250^{\circ} \mathrm{C}$, the liquid is converted to a solid polymer consisting of an alternated Si-N backbone with $\sim 80 \%$ methyl $\left(\mathrm{CH}_{3}\right)$ and $\sim 20 \%$ vinyl $\left(\mathrm{CH}=\mathrm{CH}_{2}\right)$ side groups as shown in Fig. 2 [24].

According to the manufacturer, the polymer solidifies after $2 \mathrm{~h}$ at $100^{\circ} \mathrm{C}, 1 \mathrm{~h}$ at $150^{\circ} \mathrm{C}, 40$ minutes at $200^{\circ} \mathrm{C}$ and 20 minutes at $250^{\circ} \mathrm{C}$ in air. In an inert gas atmosphere, curing takes a longer time. Curing can be accelerated by addition of dicumyl peroxide (DCPO). The dicumyl peroxide $(\geq 98 \%)$ used in this work is produced by Sigma Aldrich ${ }^{\circledR}$ and is stored in a dry, dark and cool place $\left(4^{\circ} \mathrm{C}\right)$. The chemical formula $\left(\mathrm{C}_{6} \mathrm{H}_{5} \mathrm{C}\left(\mathrm{CH}_{3}\right)_{2} \mathrm{OOC}\right.$ $\left.\left(\mathrm{CH}_{3}\right)_{2} \mathrm{C}_{6} \mathrm{H}_{5}\right)$ of DCPO, is presented in Fig. 3 that shows two benzene rings, four methyl groups $\left(\mathrm{CH}_{3}\right)$ and the classical peroxide group (O-O) [42]. Its molar mass is $270.37 \mathrm{~g} \cdot \mathrm{mol}^{-1}$.

Polysilazane and DCPO are mixed for $1 \mathrm{~h}$ at $293 \mathrm{~K}\left(20^{\circ} \mathrm{C}\right)$ using a magnetic stirrer, up to attain the complete dissolution of the peroxide and then stored at $277 \mathrm{~K}\left(4^{\circ} \mathrm{C}\right)$ for $12 \mathrm{~h}$ before testing in order to eliminate the air bubbles formed during mixing. Several dicumyl peroxide concentrations were investigated between $0.1 \mathrm{wt} \%$ and $20 \mathrm{wt} \%$.

A series of preliminary tests was conducted using a ThermoGravimetric-Analysis (TGA) coupled with a Differential Scanning Calorimetry (DSC) under dynamic conditions, with a heating rate of $10 \mathrm{~K} \cdot \mathrm{min}^{-1}$, using a TGDSC 111 of SETARAM. The study of dynamic cure kinetics change with peroxide concentration is then performed by Differential Scanning Calorimetry. All DSC tests are conducted on the compounds under

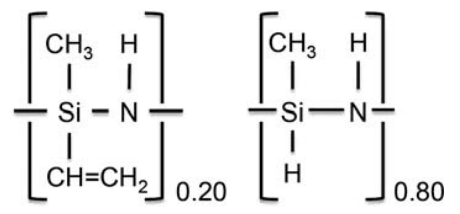

FIG. 2. Chemical structure of PSZ20 $\left(\right.$ Ceraset $\left.^{\circledR}\right)$ polymer provided by Clariant $^{\circledR}[24]$.

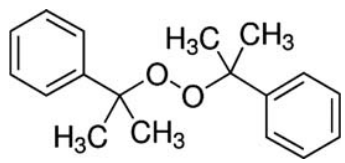

FIG. 3. Dicumyl peroxide chemical formula: $\mathrm{C}_{6} \mathrm{H}_{5} \mathrm{C}\left(\mathrm{CH}_{3}\right)_{2} \mathrm{OOC}-$ $\left(\mathrm{CH}_{3}\right)_{2} \mathrm{C}_{6} \mathrm{H}_{5}$ [42].

dynamic conditions, with a heating rate of $2 \mathrm{~K} \cdot \mathrm{min}^{-1}$. DSC tests on DCPO alone were conducted under dynamic conditions, with heating rates of $0.5,2,5$ and $10 \mathrm{~K} \cdot \mathrm{min}^{-1}$. A DSC-Q200 of TA Instruments was used to measure the specific heat of reaction $\left(\Delta H_{\text {tot }}\right)$ of the polymer and the specific heat of decomposition of the DCPO $\left(\triangle H_{\mathrm{DCPO}}\right)$. The initial mass of the samples ranges between 10 and $20 \mathrm{mg}$ and all tests were performed under continuous $\mathrm{N}_{2}$ flow $\left(50 \mathrm{ml} \cdot \mathrm{min}^{-1}\right)$ using a non-hermetic crucible. Temperature and enthalpy were calibrated with pure indium under the same conditions of heating rate, gas flow and crucible as used in the tests.

\section{RESULTS AND DISCUSSION}

\section{DCPO Decomposition}

Figure 4 depicts the results of DSC scans performed on DCPO samples at $0.5,2,5$ and $10 \mathrm{~K} \cdot \mathrm{min}^{-1}$. The heat of decomposition, $\triangle H_{D C P O}$, ranges between $1,002 \mathrm{~J} \cdot \mathrm{g}^{-1}\left(5 \mathrm{~K} \cdot \mathrm{min}^{-1}\right)$ and
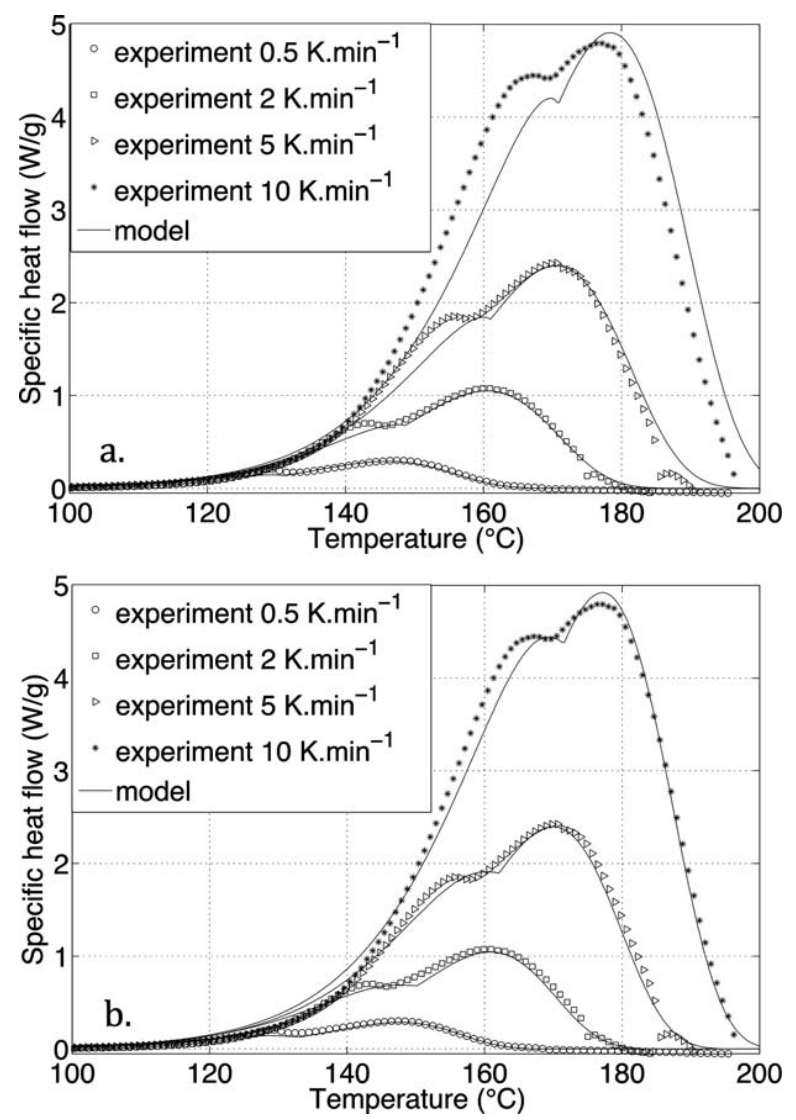

FIG. 4. Dynamic DSC analyses of DCPO decomposition at heating rates of $0.5,2,5$ and $10 \mathrm{~K} \cdot \mathrm{min}^{-1}$ and simulated results using Eq. 1 with (a), the set of parameters A and (b), the set of parameters B, (cf. Table 1). 
TABLE 1. DCPO decomposition kinetics parameters identified from the present results compared with literature data [36-41].

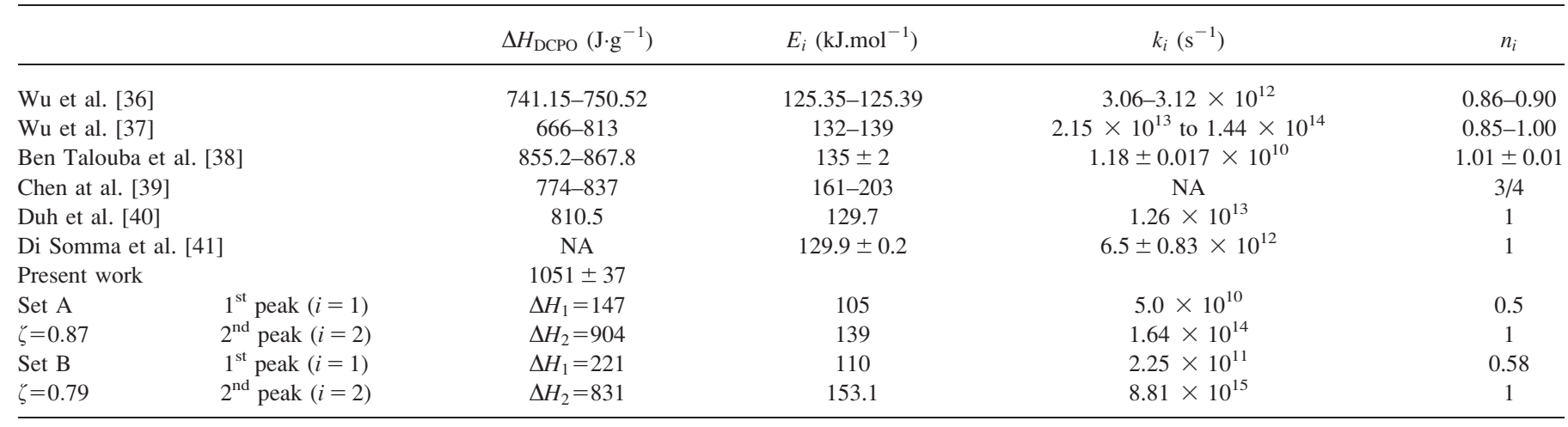

$1,091 \mathrm{~J} \cdot \mathrm{g}^{-1}\left(0.5 \mathrm{~K} \cdot \mathrm{min}^{-1}\right)$. The average value, $1,051 \pm 37$ $\mathrm{J} \cdot \mathrm{g}^{-1}$, is significantly higher than the results of other studies, between 666 and $868 \mathrm{~J} \cdot \mathrm{g}^{-1}$ [36-40]. However, the behavior is quite different with two distinct peaks, whereas literature only reports one single peak. The nature of both peaks was not further investigated in the present study. It is noteworthy that a weak secondary peak has been neglected in [40].

Actually, an $n^{\text {th }}$-order model with coefficients reported in $[36,37,40,41]$ (Table 1 ) is able to properly describe the principal peak occurring in the present experimental results (second peak occurring at higher temperature in Fig. 4). Starting from the parameters reported in $[36,37,40,41]$ (Table 1) and assuming a pseudo first-order model for the second peak, a first set of parameters, labeled $\mathrm{A}$, has been identified to fit the present experimental data with two uncoupled $n^{\text {th }}$-order model $(E q . l)$, each related to a part of the total heat of reaction $(\zeta$ for the second peak and $(1-\zeta)$ for the first one). The set of parameters A considers that $87 \%$ of $\Delta H_{\mathrm{DCPO}}$ is due to the second peak. The set of parameters $\mathrm{A}$ is within the range of values reported in [36, 37, 40, 41] (Table 1) and provides a heat of reaction for the principal peak, $\Delta H_{2}$, of $904 \mathrm{~J} \cdot \mathrm{g}^{-1}$, slightly higher than $\Delta H_{D C P O}$ values reported in [36-40].

$$
\dot{\alpha}_{D C P O}=k_{1} \cdot \mathrm{e}^{\frac{-E_{1}}{R T}} \cdot\left(1-\zeta-\alpha_{1}\right)^{n_{1}}+k_{2} \cdot \mathrm{e}^{\frac{-E_{2}}{R T}} \cdot\left(\zeta-\alpha_{2}\right)^{n_{2}}
$$

Assuming that the first peak does not affect the specific heat flow at the second one, the Kissinger method [43] was applied to identify the energy of activation. A value of $153.1 \mathrm{~kJ} \cdot \mathrm{mol}^{-1}$ was found and lead to a second set of parameters, labeled B, still assuming a pseudo first-order model for the principal peak. This method provides the best fit to experimental data and a heat of reaction $\Delta H_{2}$ of $831 \mathrm{~J} \cdot \mathrm{g}^{-1}$ (79\% of $\left.\Delta H_{\mathrm{DCPO}}\right)$ was found for the principal peak, within the range of $\Delta H_{\mathrm{DCPO}}$ reported in [36-40]. The value of $153.1 \mathrm{~kJ} \cdot \mathrm{mol}^{-1}$ for the energy of activation is significantly higher than those reported in [36-38, 40], between 125 and $139 \mathrm{~kJ} \cdot \mathrm{mol}^{-1}$. However Lv et al. [39] found a value of energy of activation between 161 and $203 \mathrm{~kJ} \cdot \mathrm{mol}^{-1}$ using the Friedman isoconvertional method.

\section{Polysilazane Crosslinking Chemistry}

The crosslinking reactions of polysilazanes involve mainly the groups $-\mathrm{CH}=\mathrm{CH}_{2}$ (vinyl), $\mathrm{Si}-\mathrm{H}$ and $\mathrm{N}-\mathrm{H}$. The main reactions, described hereinafter, are polyaddition of vinyl groups, radical reactions of methyl and vinyl groups, hydrosilylation, dehydrogenations and transamination. These reactions take place at different temperature ranges. According to Lavedrine et al. [27], the crosslinking starts at about $120^{\circ} \mathrm{C}$ with the hydrosilylation reaction (1), followed by dehydrogenation of $\mathrm{Si}-\mathrm{H}$ with $\mathrm{N}$ $\mathrm{H}$ (2). Transamination (3) takes place at approximately the same time, followed by polyaddition of vinyl groups (4), and dehydrogenation with two $\mathrm{Si}-\mathrm{H}$ groups (5). The radical reactions of methyl and vinyl groups (6) occur at higher temperature, between 200 and $300^{\circ} \mathrm{C}$ [44].

1. Hydrosilylation: $\equiv \mathrm{Si}-\mathrm{CH}=\mathrm{CH}_{2}+\equiv \mathrm{Si}-\mathrm{H} \quad \begin{gathered}\equiv \mathrm{Si}-\mathrm{CH}_{2}-\mathrm{CH}_{2}-\mathrm{Si} \equiv \\ \text { and } \\ \equiv \mathrm{Si}-\mathrm{CH}-\mathrm{Si} \equiv \\ \begin{array}{l}1 \\ \mathrm{CH}_{3}\end{array}\end{gathered}$
2. Dehydrogenation (Si-H with $\mathrm{N}-\mathrm{H}$ ):

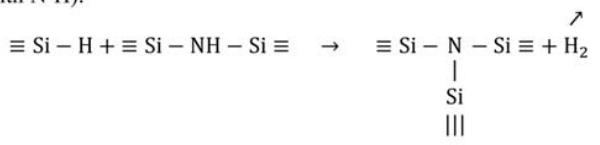

3. Transamination: $2 \equiv \mathrm{Si}-\mathrm{NH}-\mathrm{Si} \equiv \rightarrow \equiv \mathrm{Si}-\mathrm{NH}_{2}+\equiv \mathrm{Si}-\mathrm{N}-\mathrm{Si} \equiv$ (A)

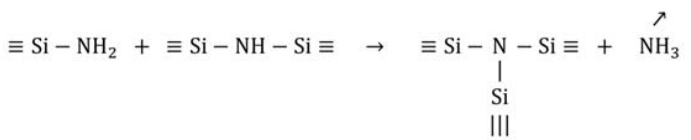

4. Polyaddition of vinyl groups:

$$
\mathrm{n}\left(\equiv \mathrm{Si}-\mathrm{CH}=\mathrm{CH}_{2}\right) \quad \rightarrow \quad-\left(\mathrm{CH}-\mathrm{CH}_{2}\right)_{n}
$$

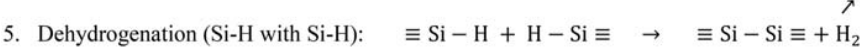

6. Methyl/vinyl radical reaction:

$$
\begin{aligned}
& \equiv \mathrm{Si}-\mathrm{CH}=\mathrm{CH}_{2}+\equiv \mathrm{Si}-\mathrm{CH}_{3} \quad \rightarrow \quad \equiv \mathrm{Si}-\mathrm{CH}_{2}-\mathrm{CH}_{2}-\mathrm{CH}_{2}-\mathrm{Si} \equiv \\
& \equiv \mathrm{Si}-\mathrm{CH}-\mathrm{CH}_{2}-\mathrm{Si} \equiv \\
& \stackrel{\mathrm{I}}{\mathrm{CH}_{3}}
\end{aligned}
$$

According to the ATG-DSC analysis conducted on the PSZ20 resin alone, no significant reaction is observed up to $200^{\circ} \mathrm{C}$ (dashed black line in Fig. 5). However according to TGA analysis (dashed grey line in Fig. 5) a mass loss of $2.5 \%$ is observed at $200^{\circ} \mathrm{C}$, which is attributed to dehydrogenation of Si$\mathrm{H}$ with $\mathrm{N}-\mathrm{H}$ groups. Above $280^{\circ} \mathrm{C}$, an exothermal reaction starts, 


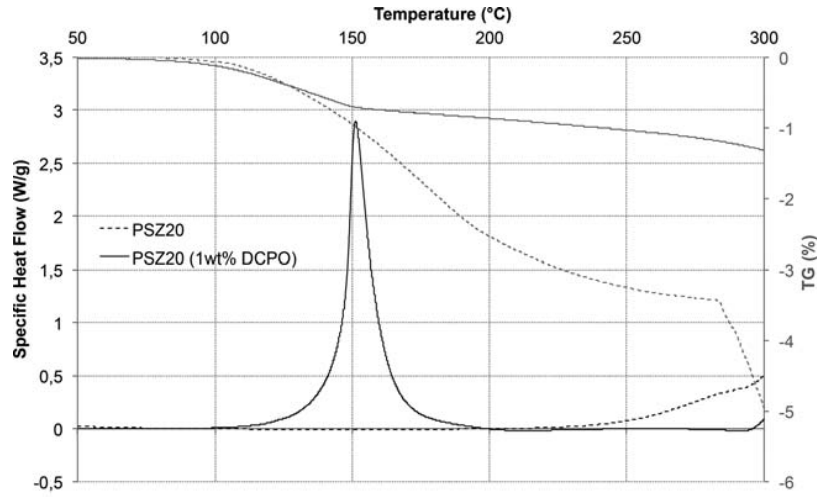

FIG. 5. TGA-DSC analyses of the PSZ20 resin alone (dashed lines) and with addition of $1 \mathrm{wt} \%$ of DCPO (continuous lines) between 50 and $300^{\circ} \mathrm{C}$, at a heating rate of $10 \mathrm{~K} \cdot \mathrm{min}^{-1}$.

with a decrease of mass, which corresponds to the reaction of transamination. The sudden mass loss is produced by the higher mass of the ammonia product $\left(\mathrm{NH}_{3}\right)$.

The polyaddition of vinyl groups can be activated at low temperature by the addition of a free radical generator as DCPO. According to the literature $[16,45]$, this reaction takes place for a temperature between 50 and $150^{\circ} \mathrm{C}$ for a polymethylvinylsilazane resin with addition of a peroxide cure initiator. After addition of $1 \mathrm{wt} \%$ of DCPO, vinyl polyaddition is promoted with regard to dehydrogenation. This inversion in the reaction order should reduce the mass loss at $200^{\circ} \mathrm{C}$. According to TGA results (continuous grey line in Fig. 5), mass loss is reduced by more than $60 \%$ at $200^{\circ} \mathrm{C}$ after addition of $1 \mathrm{wt} \%$ of DCPO, confirming literature results. A sharp exothermic peak is obtained around $150^{\circ} \mathrm{C}$.

\section{Heat of Reaction}

Figure 6 shows the dynamic DSC scans at $2 \mathrm{~K} \cdot \mathrm{min}^{-1}$ of the different tested solutions. DCPO concentration (represented by the variable $x$ ) ranges from $0.1 \mathrm{wt} \%$ to $20 \mathrm{wt} \%$. Two effects are immediately observed with the increase of DCPO concentration: a gradual decrease of the peak temperature (from $155^{\circ} \mathrm{C}$ for 0.1 wt $\%$ to $121^{\circ} \mathrm{C}$ for $20 \mathrm{wt} \%$ ), and the occurrence of a second exothermal phenomenon for a concentration higher than $3 \mathrm{wt} \%$.

In Fig. 7 are plotted the DSC scans at $2 \mathrm{~K} \cdot \mathrm{min}^{-1}$ of the compounds with $x$ values of $1,5,10$ and $20 \mathrm{wt} \%$, superimposed with the DSC scan of DCPO at $2 \mathrm{~K} \cdot \mathrm{min}^{-1}$ multiplied by the corresponding $x$ value. A strong correlation is observed between the second peak of the compound and the principal peak of DCPO decomposition (almost the same amplitude), whose kinetics turns out to be slightly faster in the compound. Owing to these results, the second peak arising in the compounds for high DCPO concentrations will be attributed to DCPO decomposition in the forthcoming interpretations.

The first exothermal peak observed for the compound is therefore related to PSZ20 crosslinking. ATG-DSC results plotted in Fig. 5 show that this peak is not correlated to a significant mass loss. Reactions with gaseous products as dehydrogenation and transamination may thus be limited in the presence of DCPO. Moreover, the radical reactions of methyl and vinyl groups are expected to occur at higher temperature, between
200 and $300^{\circ} \mathrm{C}$, according to [44]. Hydrosilylation and polyaddition of vinyl groups (promoted by DCPO) might be the principal reactions occurring in the crosslinking mechanism in the temperature range investigated.

According to this interpretation the overall heat of reaction $\left(\Delta H_{t o t}\right)$, which represents the time integral of the curves plotted in Fig. 6, can be additively decomposed into two components, related on the one hand to the contribution of PSZ20 crosslinking (initiated by DCPO) and on the other hand to DCPO decomposition. Both components depend on the variable $x$, i.e. the mass fraction of DCPO. The evolution of the overall heat of reaction is presented in Fig. 8 as a function of DCPO concentration and can be well fitted using a bilinear model (Fig. 8), with coefficients of determination of 0.999 and 0.997 respectively. According to the previous discussion regarding the initiation of vinyl group polyaddition by addition of DCPO, it is important to notice that above a certain value of DCPO concentration, the initiator will simply degrade without interacting with PSZ20, forming radicals that will not combine with vinyl groups. Both terms of the overall heat of reaction are thus proportional to the concentration in the concerned reagent, respectively PSZ20 and DCPO, leading to a linear change of the heat of reaction with x. For low DCPO concentrations (below 1.52 $\mathrm{wt} \%$ ), the overall heat of reaction is lower than expected from this linear law. This is interpreted as a lack of DCPO to interact with all the vinyl groups available in the PSZ20 to complete the crosslinking mechanism related to vinyl groups polyaddition. In any case, to attain a complete degree of polymerization, it will be necessary to heat the system at $200-300^{\circ} \mathrm{C}$, where transamination and dehydrogenation reactions will take place, involving $\mathrm{Si}-\mathrm{H}$ and N-H groups.

Above $1.52 \mathrm{wt} \%$ of DCPO, $\Delta H_{\text {tot }}$ can thus be expressed as a linear law, Eq. 2, by introducing the specific enthalpy of polymerization, $\Delta H_{p}$, and the specific enthalpy of decomposition, $\Delta H_{d}$.

$$
\Delta H_{t o t}=\Delta H_{p} \cdot(1-x)+\Delta H_{d} \cdot x \text { if } x \geq 1.52 w t \%
$$

By fitting the experimental data with $E q$. 2, it is possible to assess the value of both specific heats of reaction. For $x=0$, the intercept of $E q .2$ gives the specific heat of polymerization, $E q .3$, and the specific heat of DCPO decomposition in the compound is obtained for $x=1, E q .4$.

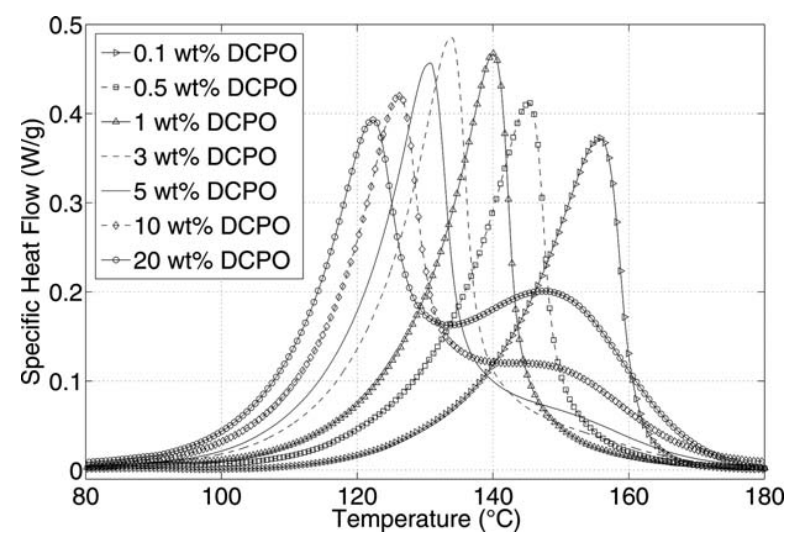

FIG. 6. Specific heat flow versus temperature of PSZ20 with several DCPO concentrations during dynamic DSC scans at $2 \mathrm{~K} \cdot \mathrm{min}^{-1}$. 

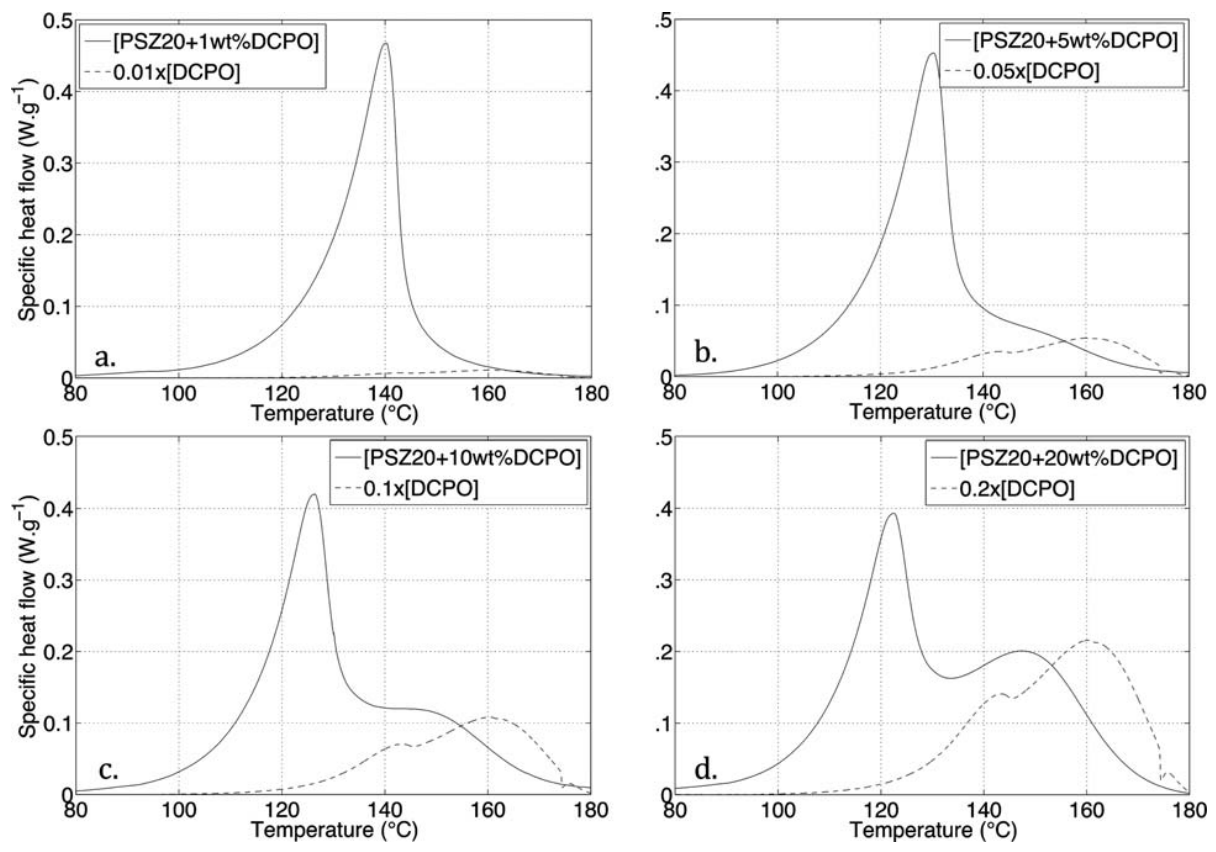

FIG. 7. Comparison of dynamic DSC scans at $2 \mathrm{~K} \cdot \mathrm{min}^{-1}$ for several compounds with various DCPO concentrations, $\mathrm{x}$, and for DCPO alone weighted by $\mathrm{x}$ : (a) $x=1 \mathrm{wt} \%$, (b) $x=5 \mathrm{wt} \%$, (c) $x=10 \mathrm{wt} \%$, and (d) $x=20 \mathrm{wt} \%$.

$$
\begin{aligned}
& \Delta H_{p}=231.87 \mathrm{~J} \cdot \mathrm{g}^{-1} \\
& \Delta H_{d}=964.92 \mathrm{~J} \cdot \mathrm{g}^{-1}
\end{aligned}
$$

As explained above, when DCPO concentration is lower than $1.52 \mathrm{wt} \%$, which represents the cross-point between both straight lines fitting the experimental data (Fig. 8), the reaction of polymerization will not be complete in the temperature range investigated, because radicals generated by DCPO decomposition will not be numerous enough to interact with all the active vinyl groups available in the system. In this low concentration range, an exponential-type function, Eq. 5, is introduced to account for the partial initiator effect in order to obtain a smooth function over the entire DCPO concentration range, instead of the bilinear one of Fig. 8 .

$$
\Delta H_{t o t}=\Delta H_{p} \cdot\left(1-A_{0} \cdot \mathrm{e}^{-\frac{x}{x_{0}}}\right) \cdot(1-x)+\Delta H_{d} \cdot x
$$

Despite its phenomenological origin, Eq. 5 can be interpreted as an increase in the probability for a vinyl group to interact with the initiator with higher DCPO concentration. $1-A_{0}$ would represent the part of all the vinyl groups available in the sample that can be initiated by a single DCPO molecule (when $x$ tends toward zero). The remaining vinyl groups (a part $A_{0}$ of the total number) would have more probability to interact with DCPO if the concentration is high, what is described by the exponentialtype function. It is noteworthy that, according to this interpretation, the value of $A_{0}$ and $x_{0}$ would probably depend on the mass of the sample and on the heating rate.

According to these considerations, Eq. 5 expresses the overall heat of reaction over the whole DCPO concentration range up to $20 \mathrm{wt} \%$ with a single continuous and smooth function. Both parameters $A_{0}$ and $x_{0}$ are identified in such a way that
Eq. 5 fits all the experimental data, providing the following values: $A_{0}=0.18$ and $x_{0}=0.009$.

The first term of Eq. 5 describes the transition from a partial polymerization of the system to a full one. The result of this equation for the overall heat of reaction is presented in Fig. 9, where the increase of DCPO concentration initially increases the heat of polymerization (exponential term), and then tends toward a linear decrease related to the decrease of PSZ20 concentration, accounted for by the term $(1-x)$. The heat of decomposition obviously increases linearly with $x$. It can be checked in Fig. 9 that the experimental data of overall heat of reaction are satisfactorily fitted by $E q .5$ using the previously identified values of $\Delta H_{p}, \Delta H_{d}, A_{0}$, and $x_{0}$.

According to this model it is possible to define the maximum degree of conversion for polymerization reaction, Eq. 6, which

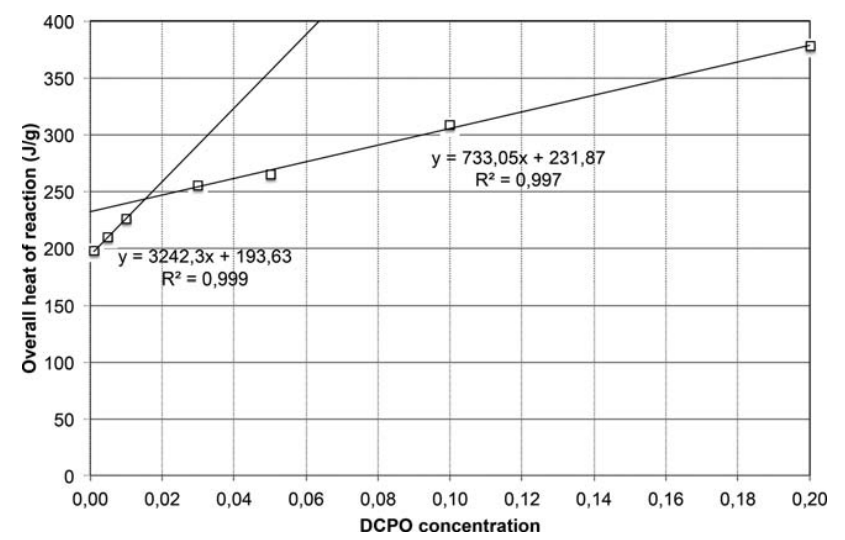

FIG. 8. Overall heat of reaction for the compound as a function of DCPO concentration. 


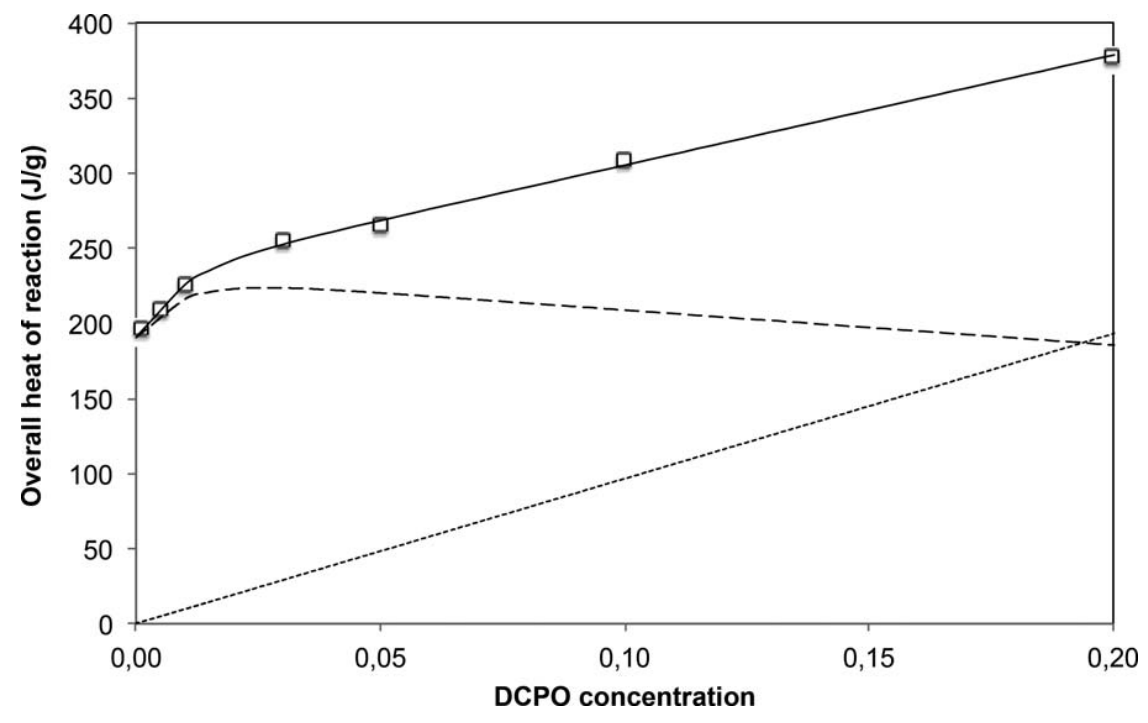

FIG. 9. Overall heat of reaction versus DCPO concentration: experimental values (squares) and results of the model (_) accounting for DCPO decomposition (...) and polymerization of PSZ20 (—), including a partial polymerization for low DCPO concentrations.

will be used in the following section to model the cure kinetics of the system as a function of DCPO concentration.

$$
\alpha_{p \max }=1-A_{0} \cdot \mathrm{e}^{-\frac{x}{x_{0}}}
$$

\section{Cure Kinetics Modeling}

In a previous work [22], cure kinetics of PSZ20 with $1 \mathrm{wt} \%$ of DCPO was modeled using a Kamal-Sourour phenomenological model [46]. The parameters were identified using several isothermal DSC scans, taking into account the initial degree of conversion of the system after an initial heating rate. This model proved to properly describe both isothermal and dynamic scans. However the effect on polymerization of DCPO concentration was not considered, because the DCPO concentration, $x$, was not included in the model. Moreover DCPO decomposition was not considered.

For these reasons a more complex phenomenological model is necessary to describe the reaction kinetics of this system, taking into account a partial degree of conversion for both reactions of polymerization and decomposition. Reaction kinetics will be modeled using two phenomenological models,

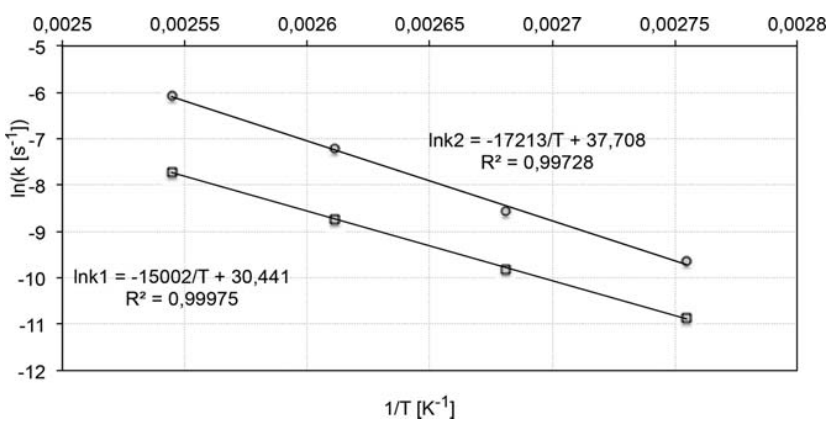

FIG. 10. Arrhenius rate constants for the Kamal-Sourour model (from isothermal DSC analyses reported in [22]). representing the decomposition of the dicumyl peroxide and the polymerization of the polysilazane.

DCPO decomposition will be modeled using an $n^{\text {th }}$-order model, Eq. 7, where $n_{d}$ is the reaction order and $k_{d}$ is the rate constant that follows an Arrhenius temperature dependence.

$$
\dot{\alpha}_{d}=k_{d} e^{\frac{-E_{d}}{R T}} \cdot\left(1-\alpha_{d}\right)^{n_{d}}
$$

This model was already successfully applied to the modeling of DCPO decomposition kinetics [36, 37, 39-41] with a reaction order close to 1 (cf. section " DCPO Decomposition" and Table 1). The activation energy ranges from 118 to $139 \mathrm{~kJ} \cdot \mathrm{mol}^{-1}$, the reaction order $n$ ranges from $3 / 4$ to 1 and the decomposition enthalpy ranges from 666 to $868 \mathrm{~J} \cdot \mathrm{g}^{-1}[36,37,39-41]$. The variability of these parameters depends on the type of identification algorithm used as well as the testing conditions. They are usually obtained for a $99 \mathrm{wt} \%$ pure DCPO, analyzed using a highpressure sealed pan to avoid evaporation during scanning. This means that the decomposition products will remain inside the capsule, interacting with the liquid DCPO (fusion point $\sim$ $50^{\circ} \mathrm{C}$ ). Such conditions of decomposition may not be representative of the decomposition that takes place in the PSZ20/DCPO solution, where further reactions that do not occur in the experiment reported in [36, 37, 39-41] could also take place. This may explain that the values of heat of decomposition obtained in $[36,37,39-41]$ differ of about 10 to $30 \%$ from the value

TABLE 2. Kamal-Sourour model parameters obtained with isothermal identification $(x=1 \mathrm{wt} \%)$ and $n^{\text {th }}$-order model parameters obtained with dynamic scans $(x=5,10$, and $20 \mathrm{wt} \%)$.

Kamal-Sourour model for polysilazane crosslinking

\begin{tabular}{lrl}
$k_{\mathrm{o} 1}=1.66 \times 10^{13} \mathrm{~s}^{-1}$ & $E_{\mathrm{a} 1}=124.73 \mathrm{~kJ} \cdot \mathrm{mol}^{-1}$ & $m=2.54$ \\
$k_{\mathrm{o} 2}=2.38 \times 10^{16} \mathrm{~s}^{-1}$ & $E_{\mathrm{a} 2}=143.12 \mathrm{~kJ} \cdot \mathrm{mol}^{-1}$ & $n=1.11$ \\
$n^{\text {th }}$-order model for DCPO decomposition (compound) & \\
$k_{\mathrm{d}}=5.00 \cdot 10^{13} \mathrm{~s}^{-1}$ & $E_{\mathrm{d}}=130.00 \mathrm{~kJ} \cdot \mathrm{mol}^{-1}$ & $n_{\mathrm{d}}=1.15$ \\
\hline
\end{tabular}



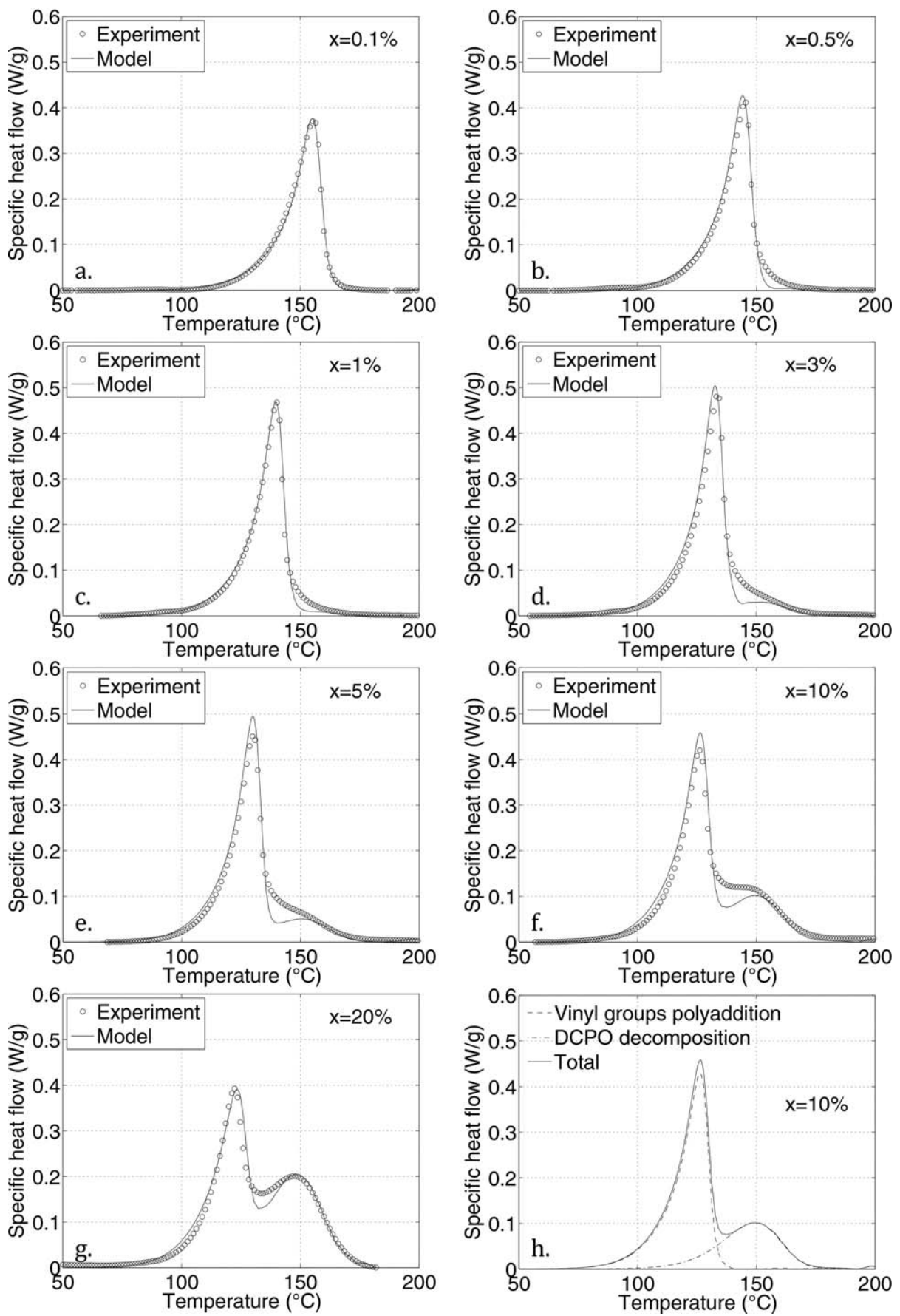

FIG. 11. Model results for several DCPO concentrations compared to experiment: (a) $x=0.1$, (b) 0.5 , (c) 1 , (d) 3 , (e) 5, (f) 10, and (g) $20 \mathrm{wt} \%$; (h) contribution of PSZ20 polymerization and DCPO decomposition to the overall heat of reaction computed for $x=10 \mathrm{wt} \%$.

identified previously with $E q$. 4. For this reason, the values of kinetics model parameters need to be identified from the present experiments performed using several compounds, even if the assumption of an $n^{\text {th }}$-order model will be considered to describe DCPO decomposition. The experimental results obtained using DCPO only have not been used to identify the parameters of Eq. 7.

PSZ20 polymerization will be modeled using a KamalSourour phenomenological model [46]. Several authors used this law to model epoxy resins polymerization [47-49] or silicone rubber vulcanization [50], because of the autocatalytic and catalytic nature of the reactions driving the crosslinking of these systems. A previous work [22] shows that this model also satisfactorily describes the kinetics behavior of the compound of PSZ20 with 1 wt $\%$ of DCPO. This model, slightly modified in Eq. 8, includes two rate constants that follow an Arrhenius temperature dependence. $m$ and $n$ are the reaction orders. The reactions whose kinetics is described by Eq. 8 are assumed to be 

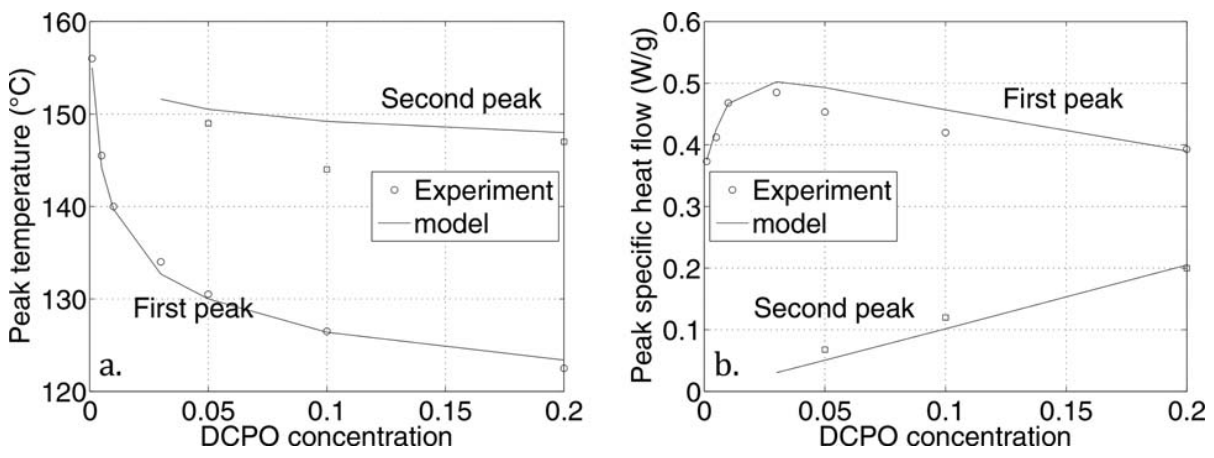

FIG. 12. Comparison of experimental and computed (a) peak temperature and (b) specific heat flow at peak for both first polymerization peak and second decomposition peak when it exists. The experimental data related to the second peak for $x=5 \mathrm{wt} \%$ are measured at the minimum slope, since there is no local maximum on this curve.

initiated by DCPO. An increase of initiator concentration acts as increasing the frequency of the interactions, and therefore increases the frequency factor and accelerates the reaction. This effect is described by the factor $\left(x / x_{\text {ref }}\right)^{w}$ added in the KamalSourour model, Eq. 8. It is noteworthy that multiplying only the catalytic term by the factor $\left(x / x_{\text {ref }}\right)^{w}$ do not allow a proper fitting of the experimental results.

$$
\dot{\alpha}_{p}=\left(\frac{x}{x_{\mathrm{ref}}}\right)^{w} \cdot\left(k_{o 1} \mathrm{e}^{\frac{-E_{a 1}}{R T}}+k_{o 2} \mathrm{e}^{\frac{-E_{a 2}}{R T}} \alpha_{p}^{m}\right)\left(\alpha_{\mathrm{pmax}}-\alpha_{p}\right)^{n}
$$

In $E q .8$, the term $\alpha_{p \max }$ allows accounting for the partial polyaddition of the vinyl groups for low DCPO concentration and for the dilution effect as a function of $x$, according to Eq. 5 . The overall heat of reaction is thus introduced as a function of $x$ by this way. However this term is not sufficient to describe the shift of peak conversion toward lower temperature with the increase of DCPO concentration. For that reason, the reaction rate, $E q .8$, includes explicitly the dependence to DCPO concentration, $x$. In $E q .8, x_{\text {ref }}$ represents the DCPO concentration previously used in [22] to identify the K-S parameters, i.e. $1 \mathrm{wt} \%$. This approach was already used in another paper [51]. In the present work, an adjustable exponent $w$ is necessary to properly fit the experimental curves over the entire DCPO concentration range.

The parameters of the PSZ20 polymerization model, Eq. 8, are identified from the isothermal DSC scans reported in [22] for a DCPO concentration of $1 \mathrm{wt} \%$. The DCPO decomposition was neglected thanks to the very low concentration in initiator; the same procedure as described in [22] was thus used, but the polymerization heat of reaction identified previously in section " Heat of Reaction" is considered, accounting for a value of $\alpha_{\text {pmax }}<1$. The rate constants for the present Kamal-Sourour corrected model, Eq. 8, are presented in Fig. 10. The parameters obtained for the Kamal-Sourour model in this paper (Table 2) are slightly different from those obtained in [22], where the effect of the model of decomposition was not taken into account and the maximal degree of polymerization was set to 1 . For this reason, in the previous work, the parameters were overestimated with regard to the present work.

The value of the adjustable parameter $w$ is obtained on the basis of the different dynamic scans with various DCPO concentrations. The value of 0.59 is identified in such a way that the temperature at the first peak matches the experiment up to $x=5$ $\mathrm{wt} \%$, i.e., PSZ20 polymerization is preponderant in the vicinity of the first peak.

The $n^{\text {th }}$-order model parameters $(E q .7)$ are identified using dynamic DSC scans in such a way that the model properly describes the end of the second peak for $x>5 \mathrm{wt} \%$, where PSZ20 polymerization can be considered as complete. An activation energy of $130 \mathrm{~kJ} \cdot \mathrm{mol}^{-1}$ is obtained, in the range identified in $[36,37,40,41]$. The value of the other parameters (Table 2) are of the same order of magnitude as those reported in $[36,37,40,41]$ (Table 1).

The parameters of this global phenomenological model, described by the set of Eqs. 5-8, identified using this procedure, are reported in Table 2. According to the parameters presented in Table 2, it is possible to plot the model results under dynamic conditions $\left(2 \mathrm{~K} \cdot \mathrm{min}^{-1}\right)$ for different DCPO concentrations (Fig. 11). The plot for $1 \mathrm{wt} \%$ (Fig. 11c) corresponds to the K-S model identified using isothermal conditions and the model of DCPO decomposition, while the other plots are obtained changing the DCPO concentration (parameter $x$ ) in Eqs. 5-8.

$$
\mathrm{q}=\Delta H_{p} \cdot(1-x) \cdot \dot{\alpha}_{p}+\Delta H_{d} \cdot x \cdot \dot{\alpha}_{d}
$$

In Fig. 11 is presented the modeled overall specific heat flow, $q, E q .9$, (computed using the MatLab ${ }^{\circledR}$ subroutine ode $15 \mathrm{~s}$ to integrate the set of Eqs. 6-9 and the experimental data (Fig. $11 \mathrm{a}-\mathrm{g}$ ). The contribution of each reaction (PSZ20 polymerization and DCPO decomposition) to the overall heat flow is plotted in Fig. 11h for a DCPO concentration of $10 \mathrm{wt} \%$ and shows that each peak is mainly related to one reaction. The model satisfactorily reproduces the shape of the first peak related to PSZ20 polymerization irrespective of the DCPO concentration, as well as the progressive occurrence of a second peak while increasing the DCPO concentration. A more quantitative comparison between model and experiment is carried out in Fig. 12, where the peak temperature is plotted against DCPO concentration (Fig. 12a). The discrepancy between the modeled and measured values of the temperature at the first peak is about $1 \mathrm{~K}$, and reaches $5 \mathrm{~K}$ for the second peak. The specific heat flow at peak (Fig. 12b) is also almost perfectly reproduced by the model, excepted for $x=3,5$, and $10 \mathrm{wt} \%$, where the value at the first peak is significantly overestimated up to $10 \%$ for $x=5 \mathrm{wt} \%$. 
Despite the satisfactorily results provided by the model concerning the global shape of the curve and the effect of DCPO concentration on the characteristics of both polymerization and decomposition peaks, a significant mismatch between experiment and model is obtained between both peaks, where the model underestimates the specific heat flow for $x \geq 0.5 \mathrm{wt} \%$. This phenomenon is probably related to the decomposition of peroxide, which may not exactly follow an $n^{\text {th }}$-order model in the compound (cf. section “ DCPO Decomposition"), and may also affect the end of polymerization. Indeed the main hypothesis of this model is that both kinetic models are completely uncoupled, neglecting the interaction between peroxide decomposition and polymerization. This model is probably too simplistic and a more mechanistic approach would be unavoidable in order to integrate polymerization dependence upon DCPO decomposition. This could be done introducing a catalytic term inside the Kamal-Sourour equation depending on the degree of conversion of DCPO decomposition. However the mechanisms ruling this phenomenon are not well understood and for this reason a more in-depth analysis should be performed, studying the decomposition/polymerization kinetics under isothermal conditions for a higher DCPO concentration (20 wt \%): under these conditions the reciprocal influence of both phenomena could be better understood and a more detailed model could be introduced.

\section{CONCLUSIONS}

The polymerization reaction of a polysilazane system was studied in presence or not of DCPO. The reaction without addition of DCPO takes place above $280^{\circ} \mathrm{C}$, driven by the reactions of transamination and polymerization of vinyl groups. To accelerate PSZ20 polymerization and reduce the peak temperature, addition of DCPO is necessary. In presence of this initiator, vinyl groups polyaddition takes place around $120-150^{\circ} \mathrm{C}$, depending on DCPO concentration. The optimal specific heat of polymerization is obtained for a concentration of $1.52 \mathrm{wt} \%$ of DCPO. Above this value the evolution of the overall heat of reaction can be described using a linear law, with a specific heat of DCPO decomposition of $964.92 \mathrm{~J} \cdot \mathrm{g}^{-1}$ and a specific heat of vinyl groups polyaddition of $231.87 \mathrm{~J} \cdot \mathrm{g}^{-1}$. Under this optimal value, a partial polyaddition reaction is observed, with a specific heat of polymerization depending on DCPO concentration through an exponential law. This describes a low probability of polyaddition initiation for low DCPO concentration. According to this interpretation it is proposed to describe the evolution of the final degree of conversion for both reactions of decomposition and polymerization. Cure kinetics is described according to two phenomenological models: an $n^{\text {th }}$-order model for the decomposition of DCPO and a modified Kamal-Sourour model for the polymerization of PSZ20. A DCPO concentration dependent term is introduced in the Kamal-Sourour model to take into account the evolution of polymerization kinetics with DCPO concentration. This model includes 14 parameters: 4 parameters describe the change in overall specific heat of reaction with DCPO concentration; 6 parameters for the KamalSourour model are identified from a complete characterization reported in [22] involving isothermal and dynamic DSC tests; 3 parameters for the $n^{\text {th }}$-order model to describe the second peak; and one parameter to match the first peak shift with changing
DCPO concentration. This model reproduces very satisfactorily the evolution of peak temperatures and intensities of both reactions, although a little mismatch between experimental data and the results of the model is observed between both peaks.

\section{ACKNOWLEDGMENTS}

The collaboration with Snecma and Herakles is gratefully acknowledged. This work was supported under the PRC Composites, French research project funded by DGAC, involving SAFRAN Group, ONERA and CNRS (Contract reference number: $1554448 \mathrm{~A})$.

\section{NOMENCLATURE}

$\alpha$ Overall degree of conversion (compound), dimensionless.

$\dot{\alpha}_{i} \quad$ Temporal derivative of $\alpha_{i}$ (reaction rate), $\mathrm{s}^{-1}$.

$\alpha_{1} \quad$ Degree of conversion for the first peak (DCPO alone), dimensionless.

$\alpha_{2}$ Degree of conversion for the second peak (DCPO alone), dimensionless.

$\alpha_{\mathrm{d}}$ Degree of DCPO degradation (compound), dimensionless.

$\alpha_{\text {DCPO }}$ Degree of degradation (DCPO alone), dimensionless.

$\alpha_{\mathrm{p}} \quad$ Degree of polymerization (compound), dimensionless.

$\Delta H_{\mathrm{d}} \quad$ Specific heat of DCPO decomposition (compound), $\mathrm{J} \cdot \mathrm{g}^{-1}$.

$\Delta H_{\mathrm{DCPO}} \quad$ Total specific heat of decomposition (DCPO alone), $\mathrm{J} \cdot \mathrm{g}^{-1}$.

$\Delta H_{\mathrm{p}} \quad$ Specific heat of polymerization reactions (compound), $\mathrm{J} \cdot \mathrm{g}^{-1}$.

$\Delta H_{\text {tot }} \quad$ Total specific heat of reaction (compound), $\mathrm{J}_{\mathrm{g}}{ }^{-1}$.

$\Delta H_{1} \quad$ Specific heat of decomposition for the first peak

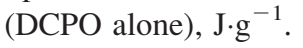

$\Delta H_{2} \quad$ Specific heat of decomposition for the second peak (DCPO alone), $\mathrm{J} \cdot \mathrm{g}^{-1}$.

$\zeta=\frac{\Delta H_{2}}{\Delta H_{D C P O}}$ Part of $\triangle H_{D C P O}$ attributed to the second peak, dimensionless.

$A_{0} \quad$ Fitting parameter of $\Delta H_{t o t}(x)$ when $x$ tends toward 0 , dimensionless.

DCPO Symbol for dicumyl peroxide.

$E_{1} \quad$ Activation energy for the first peak (DCPO alone), $\mathrm{kJ} \cdot \mathrm{mol}^{-1}$.

$E_{2} \quad$ Activation energy for the second peak (DCPO alone), $\mathrm{kJ} \cdot \mathrm{mol}^{-1}$.

$E_{a 1} \quad$ Activation energy of polymerization (catalytic component, compound), $\mathrm{kJ} \cdot \mathrm{mol}^{-1}$.

$E_{a 2} \quad$ Activation energy of polymerization (autocatalytic component, compound), $\mathrm{kJ} \cdot \mathrm{mol}^{-1}$.

$E_{d} \quad$ Activation energy of DCPO degradation (compound), $\mathrm{kJ} \cdot \mathrm{mol}^{-1}$.

$k_{01} \quad$ Pre-exponential factor for polymerization (catalytic component, compound), $\mathrm{s}^{-1}$.

$k_{02} \quad$ Pre-exponential factor for polymerization (autocatalytic component, compound), $\mathrm{s}^{-1}$.

$k_{1} \quad$ Pre-exponential factor for the first peak (DCPO alone), $\mathrm{s}^{-1}$. 
Pre-exponential factor for the second peak (DCPO alone), $\mathrm{s}^{-1}$.

$k_{\mathrm{d}} \quad$ Pre-exponential factor for DCPO degradation (compound), $\mathrm{s}^{-1}$. Pseudo-order of polymerization (autocatalytic component, compound), dimensionless.

Pseudo-order of polymerization (catalytic component, compound), dimensionless.

$n_{1} \quad$ Pseudo-order of reaction for the first peak (DCPO alone), dimensionless.

$n_{2} \quad$ Pseudo-order of reaction for the second peak (DCPO alone), dimensionless. Pseudo-order of reaction for DCPO degradation (compound), dimensionless.

PSZ20 Commercial designation of the polysilazane resin.

$q \quad$ Specific heat flow measured by DSC, $\mathrm{W} \cdot \mathrm{g}^{-1}$.

$R \quad$ Ideal gas constant, $\mathrm{J} \cdot \mathrm{mol}^{-1} \cdot \mathrm{K}^{-1}$.

$T \quad$ Temperature, $\mathrm{K}$ if not specified.

$x$ DCPO weight fraction in the compound, dimensionless.

$x_{0} \quad$ Fitting parameter of $\Delta H_{\text {tot }}(x)$ for $0<x<0.015$, dimensionless.

$x_{\text {ref }} \quad$ DCPO weight fraction used to calibrate the KamalSourour model from isothermal DSC tests in [22], dimensionless.

Fitting parameter that controls the peak temperature shift with varying $x$, dimensionless.

\section{REFERENCES}

1. P. Schutzenberger and A. Colson, C. R. Hebd. Séances Acad. Sci., 93, 1508 (1885).

2. O. Glemser, K. Beltz, and P. Naumann, Zeitschrift für Anorg. und Allg. Chemie, 291, 51 (1956).

3. B.J. Aylett, G.M. Burnett, L.K. Peterson, and N. Ross, SCI Monogr., 13, 5 (1961).

4. E. Kroke, Y.L. Li, C. Konotschny, E. Lecomte, C. Fasel, and R. Riedel, Mater. Sci. Eng., 26, 97 (2000).

5. R. Naslain, Compos. Sci. Technol., 64, 155 (2004).

6. M. Kotani, T. Inoue, A. Kohyama, K. Okamura, and Y. Katoh, Compos. Sci. Technol., 62, 2179 (2002).

7. V.M. Gudapati, V.P. Veedu, and M.N. Ghasemi-Nejhad, Compos. Sci. Technol., 66, 3230 (2006).

8. D. Seyferth and G.H. Wiseman, Commun. Am. Ceram. Soc., 27, 132 (1984).

9. Y. Blum and R.M. Laine, Organometallics, 5, 2081 (1986).

10. R.M. Laine, Platin. Met. Rev., 32, 64 (1988).

11. J.M. Schwark, Polym. Prep., 32, 567 (1991).

12. J.M. Schwark and M.J. Sullivan, Mater. Res. Soc. Proc., 271, 807 (1992).

13. D. Seyferth, C. Strohmann, N.R. Dando, and A.J. Perrotta, Chem. Mater., 7, 2058 (1995).

14. P. Colombo, G. Mera, R. Riedel, and G.D. Sorarù, J. Am. Ceram. Soc., 93, 1805 (2010).

15. F. Aldinger, M. Weinmann, and J. Bill, Pure Appl. Chem., 70, 439 (1998).

16. Y.L. Li, E. Kroke, R. Riedel, C. Fasel, C. Gervais, and F. Babonneau, Appl. Organomet. Chem., 15, 820 (2001).
17. S. Reschke, C. Haluschka, R. Riedel, Z. Lences, and D. Galusek, J. Eur. Ceram. Soc., 23, 1963 (2003).

18. E. Klatt, A. Frass, M. Friess, D. Koch, and H. Voggenreiter, $J$. Eur. Ceram. Soc., 32, 3861 (2012).

19. C. Zhou, H. Min, L. Yang, M. Chen, Q. Wen, and Z. Yu, J. Eur. Ceram. Soc., 34, 3579 (2014).

20. O. Flores, T. Schmalz, W. Krenkel, L. Heymann, and G. Motz, J. Mater. Chem. A, 1, 15406 (2013).

21. O. Flores, L. Heymann, and G. Motz, Rheol. Acta, 54, 517 (2015).

22. R. D'Elia, G. Dusserre, S. Del Confetto, N. Eberling-Fux, C. Descamps, and T. Cutard, Eur. Polym. J., 76, 40 (2016).

23. C. P. GmbH, Technical Information: Ceraset ${ }^{\circledR}$ PSZ 20, 2011.

24. Technical Bulletin 1, KiON Ceraset polyureasilazane and KiON ceraset polysilazane 20 heat-curable resins of $\mathrm{KiON}$ Corporation.

25. L.A. Liew, Y. Liu, R. Luo, T. Cross, L. An, V.M. Bright, M. Dunn, J.W. Daily, and R. Raj, Sens. Actuators A Phys., 95, 143 (2002).

26. M. Schulz, M. Borner, J. Gottert, T. Hanemann, J. Hausselt, and G. Motz, Adv. Eng. Mater., 6, 676 (2004).

27. A. Lavedrine, D. Bahloul, P. Goursat, N. Choong Kwet Yive, R. Corriu, D. Leclerq, H. Mutin, and A. Vioux, J. Eur. Ceram. Soc., 8, 221 (1991).

28. A. Kojima, S. Hoshii, and T. Muto, J. Mater. Sci. Lett., 21, 757 (2002).

29. C. Vakifahmetoglu, I. Menapace, A. Hirsch, L. Biasetto, R. Hauser, R. Riedel, and P. Colombo, Ceram. Int., 35, 3281 (2009).

30. S.A.C. Abarca, O. Flores, A.L.G. Prette, G.S. Barroso, T. Coan, G. Motz, and R.A.F. Machado, Chem. Eng. Trans., 32, 1621 (2013).

31. T. Konegger, R. Patidar, and R. Bordia, J. Eur. Ceram. Soc., 35, 2679 (2015).

32. J. Wilfert and M. Jansen, J. Mater. Chem., 21, 13422 (2011).

33. J.M. Schwark, Isocyanate- and isothiocyanate- modified polysilazane ceramic precursors. U.S. Patent, 4929704 A (1988).

34. J.M. Schwark, (Thio)amide-modified silazane polymer composition containing a free radical generator. U.S. Patent, 5155181 A (1991).

35. J.M. Schwark, Peroxide-substituted polysilazanes U.S. Patent, 5464918 A (1994).

36. K.W. Wu, H.Y. Hou, and C.M. Shu, J. Therm. Anal. Calorim., 83, 41 (2006).

37. S.H. Wu, M.L. Shyu, Y.P.I. J.H. Chi, and C.M. Shu, J. Loss Prevent. Proc., 22, 721 (2009).

38. I. Ben Talouba, L. Balland, N. Mouhab, and M.A. AbdelghaniIdrissi, J. Loss Prevent. Proc., 24, 391 (2011).

39. J. Lv, L. Chen, W. Chen, H. Gao, and M. Peng, Thermochim. Acta, 571, 60 (2013).

40. Y.S. Duh, J.M. Yo, W.L. Lee, C.S. Kao, and J.M. Hsu, J. Therm. Anal. Calorim., 118, 339 (2014).

41. I. Di Somma, R. Marotta, R. Andreozzi, and V. Caprio, J. Hazard. Mater., 187, 157 (2011).

42. Dicumyl Peroxide - National Center for Biotechnology Informations. PubChem Compound Database; $\mathrm{CID}=6641$.

43. H.E. Kissinger, Anal. Chem., 29, 1702 (1957). 
44. J. Bill, J. Seitz, G. Thurn, J. Dürr, J. Canel, B. Janos, A. Jalowiecki, D. Sauter, S. Chempp, H.P. Lamparter, J. Mayer, and F. Aldinger, Phys. Status Solidi, 166, 269 (1998).

45. G.H. Schiroky, D.V. Miller, M.K. Aghajanian, A.S. Fareed, Key Eng. Mater., 141, 127 (1997).

46. M.R. Kamal, and S. Sourour, Polym. Eng. Sci., 13, 59 (1973).

47. M. Ivankovic, L. Incarnato, J.M. Kenny, and L. Nicolais, $J$. Appl. Polym. Sci., 90, 3012 (2003).
48. F.X. Perrin, T.M.H. Nguyen, and J.L. Vernet, Eur. Polym. J., 43, 5107 (2007).

49. N. Rabearison, C. Jochum, and J.C. Grandidier, J. Mater. Sci., 46, 787 (2010).

50. L.M. Lopez, A.B. Cosgrove, J.P. Hernandez-Ortiz, and T.A. Osswald, Polym. Eng. Sci., 47, 675 (2007).

51. E. Ruiz, F. Waffo, J. Owens, C. Billotte, and F. Trochu, Modeling of resin cure kinetics for molding cycle optimization, in The 8th International Conference on Flow Processes in Composite Materials (FPCM8) - Douai, France (2006). 